AperTO - Archivio Istituzionale Open Access dell'Università di Torino

Comorbidity-adjusted relative survival in newly hospitalized heart failure patients: A populationbased study

This is a pre print version of the following article:

Original Citation:

Availability:

This version is available http://hdl.handle.net/2318/1639531

since 2017-05-27T10:41:07Z

Published version:

DOI:https://doi.org/10.1016/j.ijcard.2017.05.080

Terms of use:

Open Access

Anyone can freely access the full text of works made available as "Open Access". Works made available under a Creative Commons license can be used according to the terms and conditions of said license. Use of all other works requires consent of the right holder (author or publisher) if not exempted from copyright protection by the applicable law. 
This is the author's final version of the contribution published as:

Baldi, Ileana; Azzolina, Danila; Berchialla, Paola; Gregori, Dario; Scotti, Lorenza; Corrao, Giovanni. Comorbidity-adjusted relative survival in newly hospitalized heart failure patients: A population-based study. INTERNATIONAL JOURNAL OF CARDIOLOGY. None pp: 1-4. DOI: https://doi.org/10.1016/j.ijcard.2017.05.080

When citing, please refer to the published version.

Link to this full text:

http://hdl.handle.net/ 


\title{
Comorbidity-adjusted relative survival in newly hospitalized heart failure patients: a population-based study
}

\author{
Ileana Baldi ${ }^{1}$, Danila Azzolina ${ }^{2}$, Paola Berchialla ${ }^{3}$, Dario Gregori ${ }^{4}$, Lorenza Scotti ${ }^{5}$, Giovanni \\ Corrao $^{6}$
}

${ }^{1}$ Assistant Professor, Unit of Biostatistics, Epidemiology and Public Health, Department of Cardiac, Thoracic and Vascular Sciences, University of Padova, Via Loredan 18, 35131 Padova, Italy. This author takes responsibility for all aspects of the reliability and freedom from bias of the data presented and their discussed interpretation

${ }^{2}$ Research Assistant, Unit of Biostatistics, Epidemiology and Public Health, Department of Cardiac, Thoracic and Vascular Sciences, University of Padova, Via Loredan 18, 35131 Padova, Italy. This author takes responsibility for all aspects of the reliability and freedom from bias of the data presented and their discussed interpretation

${ }^{3}$ Assistant Professor, Department of Clinical and Biological Sciences, University of Torino, Via Santena 5bis, 10126 Torino, Italy. This author takes responsibility for all aspects of the reliability and freedom from bias of the data presented and their discussed interpretation

${ }^{4}$ Associate Professor, Unit of Biostatistics, Epidemiology and Public Health, Department of Cardiac, Thoracic and Vascular Sciences, University of Padova, Via Loredan 18, 35131 Padova, Italy. This author takes responsibility for all aspects of the reliability and freedom from bias of the data presented and their discussed interpretation

${ }^{5}$ Research Assistant, Unit of Biostatistics, Epidemiology and Public Health, Department of Statistics and Quantitative Methods, University of Milano-Bicocca, Milano, Italy. This author takes responsibility for all aspects of the reliability and freedom from bias of the data presented and their discussed interpretation

${ }^{6}$ Full Professor, Head of the Laboratory of Healthcare Research \& Pharmacoepidemiology, Department of Statistics and Quantitative Methods, University of Milano-Bicocca, Milano, Italy. This author takes responsibility for all aspects of the reliability and freedom from bias of the data presented and their discussed interpretation

Correspondence to: Dr. Ileana Baldi

Unit of Biostatistics, Epidemiology and Public Health - Department of Cardiac, Thoracic and Vascular Sciences, University of Padova - Via Loredan, 18 - 35131 Padova, Italy

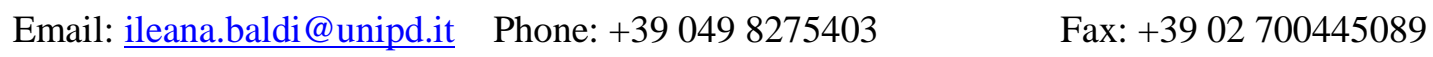

Funding: This research was partially funded by an unrestricted grant of the University of Padova, Progetti di Ateneo 2013 (Code CPDA134045/13," The role of comorbidity, disability and polypharmacy in the care of patients with heart failure").

Conflicts of Interest: The authors report no relationships that could be construed as a conflict of interest. 


\begin{abstract}
Background. This study aims to identify comorbidities through various sources and to assess their short-term impact on relative survival in a cohort of Heart Failure (HF) patients.

Methods. Newly hospitalized HF patients were identified from hospital discharge abstracts (HDA) of Lombardy Region, Italy, from 2008 to 2010. Charlson comorbidities were assessed by just HDA and supplemented by drug prescriptions and disease-specific exemptions. A Cox model for oneyear relative survival from HF was fitted.
\end{abstract}

Results. The cohort consisted of 51,061 HF patients (53\% women; median age 80 years). After integrating information from all sources, the prevalence of diabetes, chronic pulmonary disease and renal disease raised up to $27.6 \%, 26.2 \%$ and $14.2 \%$, respectively.

Survival in the HF cohort was inferior to that in the reference population and decreased with increasing number of comorbidities. Notably, the overall performance of the relative survival models was similar regardless of which strategy was used to ascertain comorbidity.

Conclusions. The effort required to implement a comprehensive search method for comorbidities is worth the potential benefit when the aim is to assess the comorbidity burden. On the contrary, a search method limited to HDA can reasonably be used to determine a comorbidity profile for mortality risk adjustment purposes.

Keywords: comorbidity; Charlson index; claims data; drug prescriptions; hospital discharges; relative survival 


\section{Introduction}

Heart Failure (HF) is a major and growing public health issue that affects all Western countries. Around $1-2 \%$ of the population in European countries suffers from HF, with the prevalence rising to above $10 \%$ among people aged 70 years and over [1].

HF is commonly accompanied by a broad range of comorbidities, with chronic kidney disease, anaemia and diabetes being the most prevalent, which further complicate the management of care, unfavourably affecting prognosis [2,3].

Research on the epidemiology of HF has relied on multiple data sources [4]. Of these, claims data have been increasingly used for health services utilization and outcome evaluation $[5,6]$.

Among methods to measure burden of comorbidity and case-mix, the Charlson comorbidity index [7] has been extensively used in claims-based investigations [8]. Nevertheless, it is recognized that administrative claims data may underestimate comorbidity burden $[9,10]$.

Some studies $[11,12]$ have explored the predictive validity of comorbidity measures when using claims data versus other clinical data sources, but few studies [9] to date have evaluated whether comorbidity-adjusted survival estimates change depending on incorporation of claims data on comorbidity from sources other than inpatient claims.

This study aims to identify comorbidities through the use of multiple administrative data sources on health care use and to assess their short-term impact on relative survival in a large Italian cohort of Heart Failure (HF) patients.

\section{Methods}

\subsection{Study population}

The Italian National Health Service (NHS) provides universal health care coverage to all Italian citizens. Essential health services are provided free of charge or at a minimal charge. Some 
particular circumstances such as disability, chronic diseases, status of inability, low income or $>65$ years of age entitle patients to co-payment fee exemption.

The reference population for this study consists of all beneficiaries of the NHS, resident in Lombardy Region, an industrialized Italian region with 10 million inhabitants. Among these, subjects firstly hospitalized with a diagnosis of HF from January 2008 to December 2010 constitute the study population.

Data are drawn from the Lombardy Health Information System, including Hospital Discharge Abstracts (HDA) database, Drugs Prescriptions Register (DPR), Disease-specific Exemptions from co-payment (DEX) and vital status.

\subsection{Algorithm to identify newly hospitalized HF cases}

Our primary definition of HF was based on diagnostic codes for heart failure (428.xx) and for hypertensive heart failure (402.01, 402.11, and 402.91), according to the International Classification of Diseases, 9th Revision, Clinical Modification (ICD-9-CM), appearing as the primary diagnosis at the first hospitalization from HDA in the study period (referred to as index admission), as suggested by a recent study in the same setting [5]. Patients who had prior hospitalization with HF diagnosis (recorded as primary or secondary diagnoses in the previous five years) were excluded.

\subsection{Ascertainment of comorbidity}

Sixteen comorbid conditions were searched in the index admission for HF and in all hospital discharges in HDA that occurred within 12 months before the index date, following the Charlson algorithm [7]. We tried to maximize sensitivity in detecting comorbidities, by integrating the information from HDA with that recorded from DPR and DEX. 
The mapping approach proposed by Huber et al [13] for detecting chronic conditions by using pharmacy data, was applied to ATC codes of medicaments dispensed at least twice within 12 months prior to the index admission.

All exemptions concerning any of the 16 conditions included in Charlson comorbidity index, still valid at the time of index admission or expired in the previous 12 months, were considered.

Table 1 lists codes used to identify comorbidity in each data source.

[ Table 1 about here]

\subsection{Statistical Analysis}

We estimated 1-year relative survival from HF through the transformation approach [14]. This method consists in a transformation of all the individual survival times to a different scale, by taking into account the general population mortality. The transformed outcome variable $(y)$ measures how long, after the HF event, and relative to the respective population, a person has lived. Population life tables of Lombardy region were provided by the Italian National Institute of Statistics.

Crude Kaplan-Meier survival probabilities, against $y$, were estimated both overall and stratified. Log-rank test was used to test survival differences.

Furthermore, we built two comorbidity-adjusted Cox survival models on the transformed outcome, including gender, age and the 16 selected comorbid conditions contributing to Charlson index. One model uses the comorbidity information assessed in HDA database only, whereas the other uses the enhanced information from all sources. We calculated the c-statistic for each model. R software, version 3.3.0 and "relsurv" package were used.

\section{Results}


A total of 51,061 incident HF subjects were identified in the years 2008-2010. The study cohort comprised predominantly women $(53.2 \%)$ and elderly patients (median age of 80 years and interquartile range from 73 to 86 years). Thirty-three thousand and twenty-one subjects $(64.7 \%)$ were entitled to a co-payment exemption.

According to HDA only, at least one Charlson comorbid condition was detected for $50.9 \%$ of the study cohort. This figure raised up to $78.2 \%$ when integrating information from all sources. Integrating HDA with DEX and DPR data mainly affected prevalence of diabetes (from $19.2 \%$ to $27.6 \%$ ), chronic pulmonary disease (from $15.2 \%$ to $26.2 \%$ ), cancer (from $6.4 \%$ to $11.1 \%$ ), rheumatic disease (from $0.9 \%$ to $17.9 \%$ ) and peptic ulcer (from $0.6 \%$ to $39.3 \%$ ). Details about the prevalence of each comorbid condition by data source are shown in Table 1.

After removing differences in structure for age, gender and calendar year, survival in the HF cohort is lower to that of the reference population (overall, $50 \%$ of HF patients died before their expected $37^{\text {th }}$ percentile) in any of the five comorbidity categories (Figure 1).

\section{[ Figure 1 about here]}

Furthermore, relative survival decreases with increasing number of comorbidities (log-rank test pvalue $<0.0001)$

Despite the discrepancies in the number of inferred comorbidities from HDA alone and in combination with DEX and DPR, the overall performance of the developed relative survival models was similar regardless of which data source was used. The difference among c-statistics was negligible, being 0.619 and 0.623 for the model with enhanced and original Charlson comorbidities, respectively.

As shown in Figure 1, subjects with major non-cardiac comorbidities such as diabetes, chronic pulmonary disease exhibited a moderate increase in the hazard for HF death.

\section{Discussion}


HF subjects typically suffer from a number of coexisting diseases that may influence the outcomes of care [2, 3, 15]. To the best of our knowledge, this is the first study (i) investigating a comprehensive search of comorbidities based on administrative data, (ii) assessing their impact on short-term survival, and (iii) trying to disentangle between mortality associated with HF from that due to all other causes through a relative survival approach.

Our findings on the major non-cardiac comorbidities in HF patients, namely diabetes, chronic pulmonary disease and renal disease, are quite in line with those reported in the literature. Our estimate of diabetes prevalence $(27.6 \%)$ is consistent with that reported from a population-based study [6] on English administrative data (26.6\%) and from the Cardiovascular Health Study [16] $(28.5 \%)$.

Renal disease prevalence (14.2\%) is slightly underestimated as compared to previous estimates [6, 16 , 17], ranging from $16.1 \%$ to $32.3 \%$, probably because DPR was not exploited to infer this comorbidity [13]. Chronic pulmonary disease burden (26.2\%) was higher than published estimates $[6,16,17]$, varying between $19 \%$ and $20 \%$, since we relied on a broader definition embracing chronic obstructive pulmonary disease and asthma as well.

We observed that integrating HDA with other sources, mostly affected the detection of patients suffering from cancer, peptic ulcer and rheumatic disease. Nevertheless, these results should be interpreted with caution because the positive predictive value of the corresponding exemption code in identifying cancer is estimated to be $86 \%$ [18] and, as to peptic ulcer and rheumatic disease, we cannot rule out that the identified prescription patterns had low specificity in detecting the conditions of interest.

The present study confirms that the high mortality observed among elderly with a first hospitalization for HF is higher than that of the reference population and is in part attributable to the impact of key baseline comorbidities. Consistently with previous findings [16], major noncardiac comorbidities exhibited a moderate increase in the hazard for HF death. Notably, the 
overall performance of the developed relative survival models was similar regardless of which data source was used to ascertain comorbidity and was consistent with published findings [13]. Some study limitations must be acknowledged. The first stems from using administrative data sources and mostly concerns coding accuracy and lack of clinical information on important predictors of cardiovascular outcomes such as ejection fraction and New York Heart Association class. The lack of clinical and lifestyle predictors, most likely justifies the low discrimination ability of the developed relative survival model [19]. Secondly, with improvements in treatment and decreases in hospital resources, more patients with HF are being managed in the community [20]. As a result, patients identified in this study through hospital discharges will probably be more representative of medically complex HF population.

Despite these limitations, this study demonstrates that the effort required to implement a comprehensive search method for comorbidities is worth the potential benefit when the aim is to assess the comorbidity burden. On the contrary, a search method, limited to HDA, data can reasonably be used to determine a profile of a HF patient's comorbidity for mortality risk adjustment purposes.

Contributions: IB designed the study and wrote the manuscript; IB and DA performed the statistical analysis; LS performed data extraction; all authors contributed to results interpretation and approved the final manuscript.

\section{References}

[1] Mosterd A, Hoes AW. Clinical epidemiology of heart failure. Heart. 2007;93:1137-46. 
[2] van Deursen VM, Urso R, Laroche C, Damman K, Dahlstrom U, Tavazzi L, et al. Co-morbidities in patients with heart failure: an analysis of the European Heart Failure Pilot Survey. Eur J Heart Fail. 2014;16:103-11.

[3] McMurray JJ, Pfeffer MA. Heart failure. Lancet. 2005;365:1877-89.

[4] Xian Y, Hammill BG, Curtis LH. Data sources for heart failure comparative effectiveness research. Heart Fail Clin. 2013;9:1-13.

[5] Corrao G, Ghirardi A, Ibrahim B, Merlino L, Maggioni AP. Short- and long-term mortality and hospital readmissions among patients with new hospitalization for heart failure: A population-based investigation from Italy. Int J Cardiol. 2015;181:81-7.

[6] Bottle A, Aylin P, Bell D. Effect of the readmission primary diagnosis and time interval in heart failure patients: analysis of English administrative data. Eur J Heart Fail. 2014;16:846-53.

[7] Charlson ME, Pompei P, Ales KL, MacKenzie CR. A new method of classifying prognostic comorbidity in longitudinal studies: development and validation. J Chronic Dis. 1987;40:373-83.

[8] de Groot V, Beckerman H, Lankhorst GJ, Bouter LM. How to measure comorbidity. a critical review of available methods. J Clin Epidemiol. 2003;56:221-9.

[9] Bang JH, Hwang SH, Lee EJ, Kim Y. The predictability of claim-data-based comorbidity-adjusted models could be improved by using medication data. BMC Med Inform Decis Mak. 2013;13:128.

[10] Lee DS, Donovan L, Austin PC, Gong Y, Liu PP, Rouleau JL, et al. Comparison of coding of heart failure and comorbidities in administrative and clinical data for use in outcomes research. Med Care. 2005;43:182-8.

[11] Mehta HB, Sura SD, Sharma M, Johnson ML, Riall TS. Comparative Performance of Diagnosisbased and Prescription-based Comorbidity Scores to Predict Health-related Quality of Life. Med Care. 2016;54:519-27.

[12] Schneeweiss S, Seeger JD, Maclure M, Wang PS, Avorn J, Glynn RJ. Performance of comorbidity scores to control for confounding in epidemiologic studies using claims data. Am J Epidemiol. 2001;154:854-64. 
[13] Huber CA, Szucs TD, Rapold R, Reich O. Identifying patients with chronic conditions using pharmacy data in Switzerland: an updated mapping approach to the classification of medications. BMC Public Health. 2013;13:1030.

[14] Stare J, Henderson R, Pohar M. An individual measure of relative survival. Journal of the Royal Statistical Society: Series C (Applied Statistics). 2005;54:115-26.

[15] Stewart S, Riegel B, Boyd C, Ahamed Y, Thompson DR, Burrell LM, et al. Establishing a pragmatic framework to optimise health outcomes in heart failure and multimorbidity (ARISE-HF): A multidisciplinary position statement. Int J Cardiol. 2016;212:1-10.

[16] Murad K, Goff DC, Jr., Morgan TM, Burke GL, Bartz TM, Kizer JR, et al. Burden of Comorbidities and Functional and Cognitive Impairments in Elderly Patients at the Initial Diagnosis of Heart Failure and Their Impact on Total Mortality: The Cardiovascular Health Study. JACC Heart Fail. 2015;3:542-50.

[17] Mentz RJ, Felker GM. Noncardiac comorbidities and acute heart failure patients. Heart Fail Clin. 2013;9:359-67, vii.

[18] Mangone L, Rashid I, Vicentini M, Bonelli LA, Borciani E, Casella C, et al. [Evaluation of the cancer co-pay fee exemption data source (048 code) to estimate cancer incidence]. Epidemiol Prev. 2015;39:226-33.

[19] Rahimi K, Bennett D, Conrad N, Williams TM, Basu J, Dwight J, et al. Risk prediction in patients with heart failure: a systematic review and analysis. JACC Heart Fail. 2014;2:440-6.

[20] James S, Barton D, O'Connell E, Voon V, Murtagh G, Watson C, et al. Life expectancy for community-based patients with heart failure from time of diagnosis. Int J Cardiol. 2015;178:268-74. 


\section{Figure legends}

Figure 1. Relative Survival analysis results. Panel A: Relative survival from HF by number of comorbidities. The estimated survival curve below/above the solid grey line indicates if the HF cohort does worse/better than the Lombardy reference population. Panel B: Forest plot of results from Cox model applied to transformed outcome $y$ (which measures how long, after the HF event, and relative to the respective population, a person has lived) in the HF cohort (CPD: Chronic pulmonary disease, CVD: Cerebrovascular disease, MI: Myocardial infarction). 


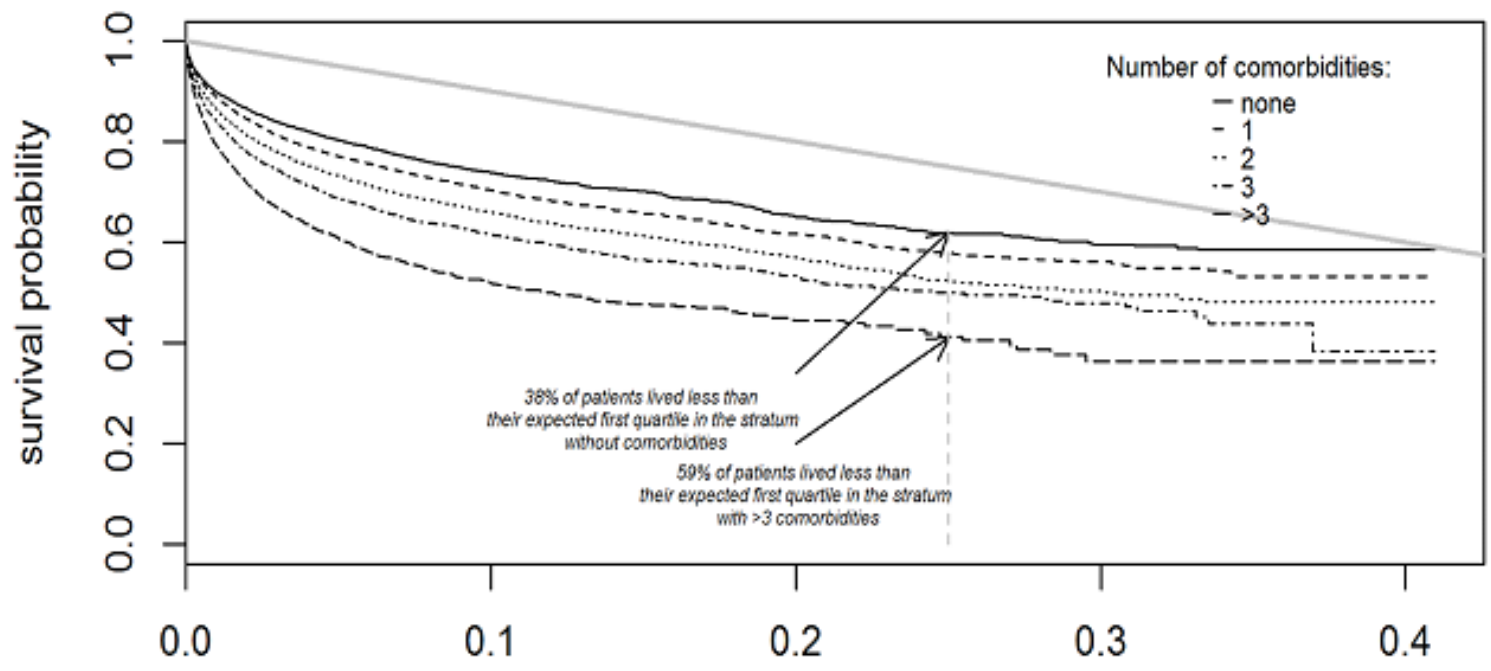

transformed outcome y

B

\begin{tabular}{|c|c|c|c|c|}
\hline \multirow{2}{*}{$\begin{array}{l}\text { Variable } \\
\text { Gender }\end{array}$} & & Hazard Ratio & \multicolumn{2}{|r|}{ p-value } \\
\hline & female & & Ref. & \\
\hline & male & & $0.95(0.92,0.99)$ & 0.0 \\
\hline Age_group & $(0,76]$ & & Ref. & \\
\hline & $(76,83]$ & & $1.02(0.97,1.07)$ & 0.5 \\
\hline & $(83,88]$ & & $1.23(1.17,1.29)$ & $<0.001$ \\
\hline & $(88,100]$ & -7 & $1.64(1.55,1.73)$ & $<0.001$ \\
\hline CPD & & & $1.15(1.11,1.19)$ & $<0.001$ \\
\hline CVD & & & $1.24(1.16,1.33)$ & $<0.001$ \\
\hline Dementia & & - & $1.81(1.64,2.00)$ & $<0.001$ \\
\hline Diabetes & & & $1.07(1.04,1.12)$ & $<0.001$ \\
\hline Hemiplegia & & & $1.80(1.54,2.12)$ & $<0.001$ \\
\hline MI & & & $1.01(0.96,1.07)$ & 0.7 \\
\hline Cancer & & & $2.11(2.02,2.20)$ & $<0.001$ \\
\hline Mild_liver & & a- & $1.34(1.19,1.52)$ & $<0.001$ \\
\hline Severe_liver & & & $2.24(1.75,2.88)$ & $<0.001$ \\
\hline Renal $^{-}$ & & D. & $1.41(1.36,1.47)$ & $<0.001$ \\
\hline Rheumatic & & & $0.91(0.87,0.95)$ & $<0.001$ \\
\hline Peptic_ulcer & & & $1.14(1.11,1.18)$ & $<0.001$ \\
\hline
\end{tabular}


Table 1. Prevalence of Charlson comorbid conditions (excluding congestive heart failure) in the HF cohort by data source along with source-specific codes.

\begin{tabular}{|c|c|c|c|c|c|c|c|}
\hline \multicolumn{2}{|l|}{ HDA } & \multicolumn{2}{|l|}{ DPR } & \multicolumn{2}{|c|}{ DEX } & \multirow{2}{*}{$\begin{array}{l}\text { HDA+D } \\
\text { EX* } \\
\mathrm{N}(\%)\end{array}$} & \multirow{2}{*}{\begin{tabular}{|l|}
$\begin{array}{l}\text { HDA+DPR+ } \\
\text { DEX* }\end{array}$ \\
$\mathrm{N}(\%)$
\end{tabular}} \\
\hline ICD-9-CM codes & $\mathbf{N}(\%)$ & ATC codes & $\begin{array}{l}\mathrm{N}( \\
\%)\end{array}$ & $\begin{array}{l}\text { ICD-9-CM } \\
\text { codes }\end{array}$ & $\mathbf{N}(\%)$ & & \\
\hline $\begin{array}{l}\text { Diabetes without } \\
\text { complications } \\
250,250.0 x-250.3 x, 250.7 x\end{array}$ & $7,841(15.4)$ & $\begin{array}{l}\text { Diabetes } \\
\text { mellitus } \\
\text { A10A, }\end{array}$ & $\begin{array}{l}11,0 \\
97 \\
(21\end{array}$ & $\begin{array}{l}\text { Diabetes } \\
\text { mellitus }\end{array}$ & $\begin{array}{l}11,422 \\
(22,4)\end{array}$ & $\begin{array}{l}13,457 \\
(26,3)\end{array}$ & $14,113(27.6)$ \\
\hline $\begin{array}{l}\text { Diabetes with complications } \\
250.4 x-250.6 x, 250.8 x-250.9 x\end{array}$ & $1,959(3.8)$ & $\begin{array}{l}\text { A10B } \\
\text { A10X }\end{array}$ & 7) & 250 & & & \\
\hline $\begin{array}{l}\text { Chronic pulmonary disease } \\
490 . x x-496,500-505,506.4\end{array}$ & $7,765(15.2)$ & $\begin{array}{l}\text { Respirator } \\
\text { y illness } \\
\text { R03 }\end{array}$ & $\begin{array}{l}9,62 \\
7 \\
(18 . \\
8)\end{array}$ & $\begin{array}{l}\text { Asthma } \\
493\end{array}$ & $211(0.4)$ & $\begin{array}{l}7,867 \\
(15.4)\end{array}$ & $13,367(26.2)$ \\
\hline $\begin{array}{l}\text { Renal disease } \\
\text { 582.xx, 583.xx, 585.x, 586, } \\
\text { 588.xx }\end{array}$ & 6,849 (13.4) & --- & -- & $\begin{array}{l}\text { Chronic kidney } \\
\text { disease } \\
585\end{array}$ & $1143(2.2)$ & $\begin{array}{l}7,241 \\
(14.2)\end{array}$ & $7,241(14.2)$ \\
\hline $\begin{array}{l}\text { Myocardial infarction } \\
410 . x x, 412\end{array}$ & $4,806(9.4)$ & --- & --- & --- & --- & $\begin{array}{l}4,806 \\
(9.4)\end{array}$ & $4,806(9.4)$ \\
\hline $\begin{array}{l}\text { Any malignancy, } \\
\text { including lymphoma and } \\
\text { leukemia, } \\
\text { except malignant neoplasm of } \\
\text { skin } \\
\text { 140.x-171.x, 174.x.-195.x, } \\
\text { 200.x-208.x, } \\
273.3, V 10.46\end{array}$ & $2,582(5.1)$ & $\begin{array}{l}\text { Cancer } \\
\text { L01 }\end{array}$ & $\begin{array}{l}606 \\
(1.2)\end{array}$ & $\begin{array}{l}\text { Tumour } \\
048\end{array}$ & $3,966(7.7)$ & $\begin{array}{l}5,431 \\
(10.6)\end{array}$ & $5,743(11.2)$ \\
\hline $\begin{array}{l}\text { Metastatic solid tumor } \\
\text { 196.x-199.x }\end{array}$ & $692(1.3)$ & & & & & & \\
\hline $\begin{array}{l}\text { Peripheral vascular disease } \\
\text { 441.xx, 443.9, 785.4, V43.4; } \\
\text { Procedures } 38.13,38.14,38.16 \text {, } \\
\text { 38.18, 38.43, 38.44, 38.46, } \\
38.48,38.33,38.34,38.36, \\
38.38,39.22-39.26,39.28, \\
39.29\end{array}$ & $2,487(4.9)$ & --- & --- & $\begin{array}{l}\text { Diseases of } \\
\text { arteries, } \\
\text { arterioles, and } \\
\text { capillaries } \\
441.2,441.4, \\
441.7,441.9, \\
\text { V43.4 }\end{array}$ & $302(0.6)$ & $\begin{array}{l}2,694 \\
(5.3)\end{array}$ & $2,727(5.3)$ \\
\hline $\begin{array}{l}\text { Cerebrovascular disease } \\
\text { 430-437.x, 438; } \\
\text { Procedures } 38.12,38.42\end{array}$ & $2,280(4.5)$ & --- & --- & $\begin{array}{l}\text { Cerebrovascula } \\
\text { r disease } \\
433,434,437\end{array}$ & $272(0.5)$ & $\begin{array}{l}2,485 \\
(4.9)\end{array}$ & $2,485(4.9)$ \\
\hline $\begin{array}{l}\text { Mild liver disease } \\
571.2,571.4 x-571.6\end{array}$ & $918(1.8)$ & --- & --- & $\begin{array}{l}\text { Chronic liver } \\
\text { disease } \\
\text { and cirrhosis }\end{array}$ & $0(0.0)$ & $918(1.8)$ & $918(1.8)$ \\
\hline
\end{tabular}




\begin{tabular}{|c|c|c|c|c|c|c|c|}
\hline & & & & $\begin{array}{ll}571.2, & 571.5, \\
571.6 & \\
571.4 & \end{array}$ & & & \\
\hline $\begin{array}{l}\text { Moderate or severe liver } \\
\text { disease } \\
456.0-456.21,572.2-572.8 \text {; } \\
\text { Procedures } 39.1,42.91\end{array}$ & $140(0.3)$ & --- & --- & --- & --- & $140(0.3)$ & $140(0.3)$ \\
\hline $\begin{array}{l}\text { Dementia } \\
290 . x x\end{array}$ & $560(1.1)$ & $\begin{array}{l}\text { Dementia } \\
\text { N06D }\end{array}$ & $\begin{array}{l}352 \\
(0.7)\end{array}$ & $\begin{array}{l}\text { Dementia } \\
290.0-290.2 \\
290.4\end{array}$ & --- & $560(1.1)$ & 830 (1.6) \\
\hline $\begin{array}{l}\text { Rheumatic disease } \\
710.0, \quad 710.1, \quad 710.4, \quad 714.0- \\
714.2,714.81,725\end{array}$ & $437(0.9)$ & $\begin{array}{l}\text { Rheumatol } \\
\text { ogic } \\
\text { conditions } \\
\text { M01, M02, } \\
\text { L04AA, } \\
\text { L04AB }\end{array}$ & $\begin{array}{l}8,86 \\
5 \\
(17 . \\
4)\end{array}$ & $\begin{array}{l}\text { Rheumatoid } \\
\text { arthritis } \\
714.0-714.2\end{array}$ & --- & $437(0.9)$ & 9,131 (17.9) \\
\hline $\begin{array}{l}\text { Hemiplegia or paraplegia } \\
342 . x x, 344.1\end{array}$ & $350(0.7)$ & --- & --- & --- & --- & $350(0.7)$ & $350(0.7)$ \\
\hline $\begin{array}{l}\text { Peptic ulcer disease } \\
\text { 531.xx-534.xx }\end{array}$ & $298(0.6)$ & $\begin{array}{l}\text { Acid } \\
\text { related } \\
\text { disorders } \\
\text { A02 }\end{array}$ & $\begin{array}{l}24,3 \\
22 \\
(47 . \\
6)\end{array}$ & --- & --- & $298(0.6)$ & $20,071(39.3)$ \\
\hline $\begin{array}{l}\text { AIDS/HIV } \\
042 . x-044 . x\end{array}$ & $18(0.0)$ & $\begin{array}{l}\text { HIV } \\
\text { J05AE, } \\
\text { J05AG, } \\
\text { J05AR }\end{array}$ & $\begin{array}{l}0 \\
(0.0)\end{array}$ & $\begin{array}{l}\text { HIV disease } \\
042\end{array}$ & $0(0.0)$ & $18(0.0)$ & $18(0.0)$ \\
\hline
\end{tabular}

*: a comorbidity appearing in more than one source is counted once per patient. 


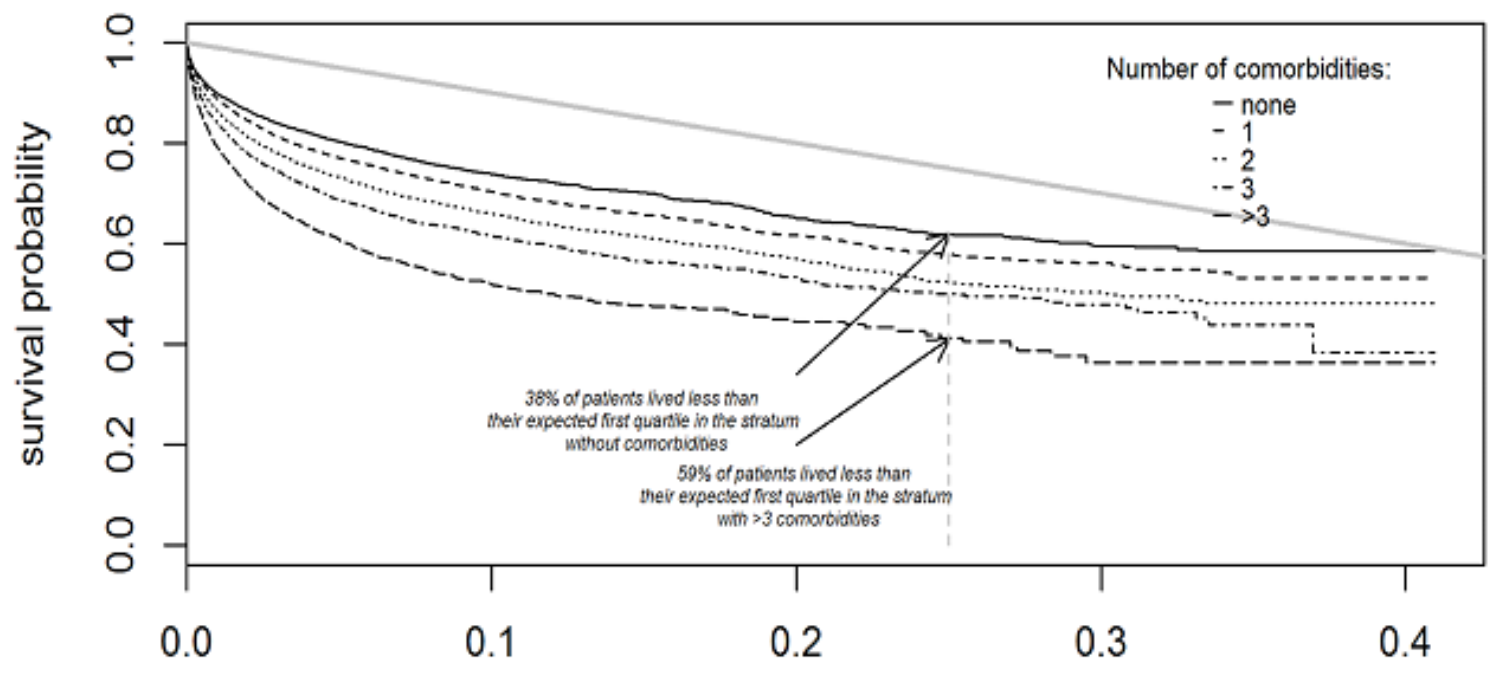

transformed outcome y

B

\begin{tabular}{|c|c|c|c|c|}
\hline Variable & & Hazard Ratio & & p-value \\
\hline \multirow[t]{2}{*}{ Gender } & female & & Ref. & \\
\hline & male & & $0.95(0.92,0.99)$ & 0.0 \\
\hline \multirow[t]{4}{*}{ Age_group } & $(0,76]$ & & Ref. & \\
\hline & $(76,83]$ & & $1.02(0.97,1.07)$ & 0.5 \\
\hline & $(83,88]$ & & $1.23(1.17,1.29)$ & $<0.001$ \\
\hline & $(88,100]$ & & $1.64(1.55,1.73)$ & $<0.001$ \\
\hline CPD & & & $1.15(1.11,1.19)$ & $<0.001$ \\
\hline CVD & & 十 & $1.24(1.16,1.33)$ & $<0.001$ \\
\hline Dementia & & & $1.81(1.64,2.00)$ & $<0.001$ \\
\hline Diabetes & & & $1.07(1.04,1.12)$ & $<0.001$ \\
\hline Hemiplegia & & & $1.80(1.54,2.12)$ & $<0.001$ \\
\hline MI & & & $1.01(0.96,1.07)$ & 0.7 \\
\hline Cancer & & & $2.11(2.02,2.20)$ & $<0.001$ \\
\hline Mild_liver & & - & $1.34(1.19,1.52)$ & $<0.001$ \\
\hline Severe_liver & & & $2.24(1.75,2.88)$ & $<0.001$ \\
\hline Renal $^{-}$ & & 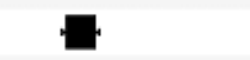 & $1.41(1.36,1.47)$ & $<0.001$ \\
\hline Rheumatic & & & $0.91(0.87,0.95)$ & $<0.001$ \\
\hline Peptic_ulcer & & & $1.14(1.11,1.18)$ & $<0.001$ \\
\hline
\end{tabular}

